\title{
Representações sociais de discentes de graduação em enfermagem sobre "ser enfermeiro"
}

\author{
Social representations of Nursing students about "being nurse"
}

Representaciones sociales de alumnos de graduación en Enfermería sobre "ser enfermero"

\section{Aneilde Maria Ribeiro de Brito', Maria José Menezes Brito", Maria Flávia Carvalho Gazzinelli", Lívia Cozer Montenegro"'I}

' Universidade José do Rosário Vellano (UNIFENAS). Universidade Federal de Minas Gerais. Escola de Enfermagem. Núcleo de Pesquisa em Administração e Enfermagem - NUPAE (Membro). Belo Horizonte-MG, Brasil.

"Universidade Federal de Minas Gerais. Escola de Enfermagem.

Núcleo de Pesquisa em Administração e Enfermagem - NUPAE. Belo Horizonte-MG, Brasil.

III Universidade Federal de Minas Gerais. Escola de Enfermagem.

Programa de Pós-Graduação em Enfermagem (Mestranda). Belo Horizonte-MG, Brasil.

Submissão: 21/02/2010 Aprovação: 12/12/2010

\section{RESUMO}

O objetivo do estudo foi analisar as estruturas das representações sociais sobre "ser enfermeiro" de 430 discentes dos cursos de Enfermagem de cinco Instituições de Ensino Superior privadas de Belo Horizonte-MG, criadas no período de 2003 a 2004. A coleta de dados ocorreu no período de 2003 a 2004, a partir da técnica de evocação livre; os dados foram processados pelo software EVOC (versão 2003) e analisados pela técnica do quadro de quatro casas. Nesta metodologia, os elementos do núcleo central foram os termos cuidar e responsabilidade, e os elementos periféricos, gerenciar, profissionalismo, trabalho, realização, atenção e respeito, demonstrando que a carga histórica da Enfermagem ainda persiste nos dias atuais, moldando-a em um saber e um fazer específico, ligado aos sentimentos e comportamentos valorizados e norteados por aspectos humanos, éticos e religiosos. Descritores: Enfermagem; Estudantes de Enfermagem; Escolas de Enfermagem; Psicologia Social.

\section{ABSTRACT}

The aim of this study was to analyze the social representations structures about "being nurse" of 430 nursing students of five private educational institutions of Belo Horizonte-MG, created between 2003 and 2004. The data collection occurred using free evocation techniques; the data were processed by the software EVOC (2003 version) and analyzed by the four house board technique. The central nucleus elements were caring and responsibility, while peripheral elements were management, professionalism, work, realization, attention and respect. Those results show that the nursing historical load still persists, shaping the profession into a specific knowledge and work, linked to feelings and behaviors influenced by human, ethical and religious aspects.

Key words: Nursing, Nursing Students, Nursing School, Social Psychology.

\section{RESUMEN}

Este estudio tuve como objetivo analizar las estructuras de las representaciones sociales sobre "ser enfermero" de 430 alumnos de Enfermería de cinco Instituciones de Enseñanza Superior privadas de la ciudad de Belo Horizonte-MG, creadas en el período de 2003 a 2004. La recogida de datos ocurrió en el período de 2003 a 2004, usándose la técnica de evocación libre; los datos fueron procesados por el software EVOC (versión 2003) y analizados por la técnica del cuadro de cuatro casas. Los elementos del núcleo central fueron los términos cuidar y responsabilidad, y los elementos periféricos fueron gestionar, profesionalismo, trabajo, realización, atención y respecto. Los resultados muestran que la carga histórica de la Enfermería aun persiste, influenciando el saber y el hacer específico, ligado a los sentimientos y comportamientos valorados y norteados por aspectos humanos, éticos e religiosos. Palabras clave: Enfermería, Estudiantes de Enfermería, Escuelas de Enfermería, Psicología Social. 


\section{INTRODUÇÃO}

Face às aceleradas mudanças econômicas e sociais e ao acentuado avanço científico e tecnológico da atualidade, rápidas transformações ocorrem em todos os setores da sociedade. Neste sentido o processo de reestruturação do setor saúde favoreceu transformações também no ensino da Enfermagem, apontando a necessidade de mudanças nos cursos de graduação e a consequente articulação com os serviços.

$\mathrm{O}(\mathrm{a})$ enfermeiro(a) passa a assumir, de maneira efetiva, ações interdisciplinares, orientado(a) pelos princípios doutrinários do Sistema Único de Saúde (SUS), regulamentado pela Lei $n^{\circ} 8.080$ em 19 de setembro de 1990. Esses princípios são a universalização, a equidade e a integralidade e, como princípios organizativos, a regionalização e a hierarquização, a descentralização, o comando único e a participação popular no modelo assistencial e preventivo proposto para toda a população brasileira $^{(1)}$.

Vislumbra-se, a partir daí, novas exigências para o (a) profissional da Enfermagem, pois as novas práticas requerem uma abordagem generalista, crítico-reflexiva, e profissionais capazes de reorganizar o processo de trabalho, operacionalizar o SUS e realizar ações interventivas concretas para a população, conforme suas necessidades ${ }^{(2)}$.

Desde então, questionar e redirecionar os marcos referenciais e conceituais dos currículos tem constituído um desafio para os gestores do ensino de instituições formadoras, tendo em vista a relevância das instituições de ensino de Enfermagem como espaços de construção e circulação de saberes que possibilitem a transversalidade do conhecimento.

Por um lado, há grande expansão de cursos novos que reproduzem currículos inflexíveis, sem a integração de saberes conforme proposto pelas Diretrizes Curriculares Nacionais para os Cursos de Enfermagem, e por outro lado há os cursos tradicionais que se esforçam para adequar seus currículos em curtos períodos de tempo, procurando acompanhar as várias discussões em âmbito nacional, que tratam de currículos coerentes com conhecimentos, competências e atitudes levando em consideração a articulação vertical e horizontal de saberes.

Nos últimos seis anos, o número de cursos de graduação em Enfermagem apresentou um crescimento de $218 \%$, passando para 582 cursos, sendo $18 \%$ em instituições federais e $82 \%$ em instituições privadas ${ }^{(3)}$. Esse dado é mais preocupante quando analisado segundo regiões. Tome-se como exemplo o Estado de Minas Gerais, que possuía, até o ano de 2000, 16 cursos de Graduação em Enfermagem e, em dezembro de 2007, já apresentava 112 cursos, o que corresponde a um crescimento de aproximadamente $600 \%{ }^{(3)}$.

A expansão do sistema de ensino superior ocorreu principalmente nas instituições privadas, o que expressa a tendência mercadológica da educação superior e a consequente valorização do mercado econômico como elemento fundamental na criação de novos cursos e instituições. Este fato é apontado como um novo desafio para o processo educativo(4):

[...] a globalização educacional e a internacionalização do conhecimento, em resposta aos desafios da globalização econômica, trazem consigo o enorme desafio de a educação superior conciliar as exigências de qualidade e inovação com as necessidades de ampliar o acesso e diminuir as assimetrias sociais.

A partir de uma percepção governamental de que a universidade pública não conseguiria suprir a demanda reprimida por educação superior no país, o atual Plano Nacional de Educação (PNE) define que é essencial que haja planejamento na expansão dos cursos superiores privados no país, para evitar a sua massificação, pois, caso contrário, a qualidade do ensino e, consequentemente, a qualidade da assistência serão irremediavelmente comprometidas ${ }^{(4)}$, o que fere os princípios da política de saúde atual.

Neste contexto, as Novas Diretrizes Curriculares, suscitam mudança de paradigma na educação em Enfermagem, assumindo como base filosófica os quatro pilares da educação, ou seja, de forma que leve "os alunos a aprender a aprender que engloba aprender a ser, aprender a fazer, aprender a viver juntos e aprender a conhecer"(5). Busca-se, portanto, a formação de profissionais autônomos, capazes de discernimento para garantir assistência integral e de qualidade, baseada na humanização do atendimento prestado aos indivíduos, famílias e comunidades.

O enfermeiro, dentro dessa filosofia, deve ter responsabilidade política e profissional e realizar um trabalho cuja intenção seja tornar-se agente de transformação social. Para isso, a educação deve ser entendida como prática social que contribua para o desenvolvimento do indivíduo na sua integralidade, possibilitando ações transformadoras na construção de cidadãos $^{(6)}$.

Nessa ótica, alguns aspectos referentes à imagem da Enfermagem como profissão histórica e socialmente construída influenciam nas escolhas e no comportamento dos profissionais enfermeiros, afetando a percepção que esses sujeitos têm de si e dos papéis que assumem na sociedade.

A constatação da expansão dos cursos de Enfermagem nos últimos anos, com consequente aumento no número de alunos matriculados, induziu-nos a questionar o que pensam os discentes de enfermagem a respeito da profissão. Esse entendimento vai ao encontro da preocupação constante em formar profissionais críticos e conscientes de seu papel social, comprometidos com as reais necessidades de vida e saúde da população. Portanto, o objetivo deste estudo foi investigar as representações sociais sobre "ser enfermeiro" de discentes de Enfermagem de Instituições de Ensino Superior (IES) privadas de Belo Horizonte-MG, criadas no período de 2003 a 2004.

\section{METODOLOGIA}

O cenário de estudo desta pesquisa constituiu-se de cinco IES privadas, localizadas no município de Belo Horizonte_MG. O contato com essas instituições foi realizado, inicialmente, a partir do contato com os coordenadores de cada curso segundo sua disponibilidade. Posteriormente, estabeleceu-se contato com os docentes e discentes, em horário de aula, previamente agendado pelo coordenador e 
ou professor, culminando na apresentação e aplicação dos questionários. Ressalta-se que cada instituição foi relacionada segundo ordem numérica, mantendo-se, assim, o anonimato dos participantes.

No período da realização da pesquisa, essas instituições apresentavam um total de 4.480 discentes matriculados em todos os períodos. Assim, foram convidados discentes do $1^{\circ}$ e $6^{\circ}$ períodos do Curso de Enfermagem das IES em estudo (o que representava um universo de 1.062 discentes) que concordassem em participar da pesquisa.

A escolha dos discentes do $1^{\circ}$ período se justifica mediante o fato de serem ingressantes, sendo possível inferir que não possuíam uma visão clara do ser enfermeiro. Quanto à escoIha dos discentes do $6^{\circ}$ período, acredita-se que, nessa etapa do curso, já obtiveram informações e conhecimento teórico-práticos que os possibilitam uma visão mais clara e ampliada sobre ser enfermeiro.

O período de coleta de dados estendeu-se de 28 de maio a 29 de junho de 2007 e os dados foram obtidos por meio da técnica de evocação livre, por meio da qual buscou-se apreender as representações sociais desses discentes por meio do termo indutor "ser enfermeiro".

Sobre a técnica de evocação livre, considera-se as propriedades quanti-qualitativas no levantamento dos possíveis elementos centrais e periféricos de uma representação social ${ }^{(7)}$. A aplicação dessa técnica consistiu em solicitar aos discentes que escrevessem cinco palavras ou expressões que lhes viessem à lembrança, por meio de métodos associativos ou evocações relacionadas ao termo indutor "ser enfermeiro". Foi solicitado, em seguida, que enumerassem os termos produzidos em suas respostas segundo o grau de importância (hierarquia), do mais importante para o menos importante, em uma escala de um a cinco, o que permitiu, por meio do cálculo das frequências, a determinação dos elementos centrais e periféricos.

As estruturas obtidas por meio das evocações livres foram analisadas pela técnica do quadro de quatro casas, criado por Pierre Vergès ${ }^{(8)}$. O quadro de quatro casas descreve o núcleo central (elementos mais frequentes e mais importantes situados no quadrante superior esquerdo); os elementos intermediários ou $1^{\text {a }}$ periferia (elementos periféricos mais importantes situados no quadrante superior direito); os elementos de contraste (com baixa frequência, mas considerados importantes pelos sujeitos, situados no quadrante inferior esquerdo); e os elementos periféricos da representação ou $2^{\mathrm{a}}$ periferia (menos freqüentes e menos importantes, localizados no quadrante inferior direito) ${ }^{(8)}$.

Para a construção desse quadro, foi utilizado o software EVOC (Ensemble de Programmes Permettant L'Analyse des Evocations), versão 2003. Trata-se de um programa de informática que permite a emissão de dados estatísticos para posterior análise qualitativa de evocações por meio da verificação de frequências simples de ocorrência de cada palavra evocada, da média ponderada da ocorrência de cada palavra em função da ordem de evocação e da média das ordens ponderadas do conjunto dos termos evocados ${ }^{(9)}$. Também permite incluir variáveis que caracterizam os sujeitos da pesquisa, possibilitando a análise do material obtido e a distinção dos indivíduos formando grupos a partir das respostas dadas ${ }^{(8)}$.
Para obter o corpus de análise, foram digitadas, em formato Excel, todas as evocações coletadas em sua forma original, segundo modelo ${ }^{(9)}$. Posteriormente, para homogeneizar o conteúdo semântico, visando a uma análise mais consistente, procedeu-se a uma padronização das palavras e termos evocados. Com base na planilha Excel, foram organizadas, em arquivo Word, todas as evocações classificadas em ordem alfabética, agrupando-se as palavras por proximidade semântica.

Os termos padronizados foram organizados em forma de dicionário, seguindo o padrão de termo escolhido com padronização na coluna esquerda, acompanhado por todas as palavras relacionadas sob a mesma designação na coluna na direita, assegurando que o sentido expresso por elas ficasse contemplado e, ao mesmo tempo, fosse processado pelo software como sinônimo.

Em seguida, na planilha corpus original, formato Excel, as palavras evocadas em suas formas originais foram substituídas pelas palavras padronizadas, uma de cada vez, a partir do dicionário. Posteriormente, foi elaborado o corpus final, a partir da planilha Excel, salva no programa Bloco de Notas (somente texto), formato lido pelo software EVOC, versão 2003. Lembramos que esse software é um instrumento fundamental para organizar e tratar os dados textuais, permitindo sistematizar tanto a análise estatística das palavras quanto a análise qualitativa subsequente.

A partir do dicionário de palavras produzidas pela população em estudo, o software calculou e informou a "frequência simples de ocorrência de cada palavra evocada, a média ponderada de ocorrência de cada palavra em função da ordem de evocação e a média das ordens médias ponderadas do conjunto dos termos evocados"(8).

No que diz respeito aos aspectos éticos, foram respeitados seus princípios em conformidade com a Resolução CNS 196/196 ${ }^{(10)}$, sobre Diretrizes e Normas Regulamentadoras de Pesquisa envolvendo Seres Humanos do Ministério da Saúde (ETIC n049/07).

\section{RESULTADOS E DISCUSSÃO}

Participaram do estudo 430 discentes, o que consistiu num total de $9,6 \%$ do total de discentes de enfermagem das cinco IES selecionadas. Ressalta-se que, no período de realização da pesquisa, o número de discentes de IES do $1^{\circ}$ período totalizava 695 discentes e do $6^{\circ}$ período, 367 discentes.

Inicialmente, o produto das evocações dos discentes constituiu-se num dicionário (corpus de análise) com total de 2.139 referências, incluindo palavras cognatas ou expressões de mesmo sentido, das quais 107 foram diferentes. A ordem média de evocação (rang) foi igual a 2,99, sendo arredondado para 3, ao passo que a frequência média ficou situada em 107 e a mínima 60.

Posteriormente, as palavras ou blocos de texto citados foram condensados conforme a afinidade conceitual existente entre os construtos, dando origem a 12 categorias que compõem o conteúdo das representações sociais dos participantes acerca do objeto pesquisado, ser enfermeiro. Essas categorias encontram-se ordenadas em quatro casas $^{(11)}$ dispostas conforme frequência e ordem média das evocações (Quadro 1). 


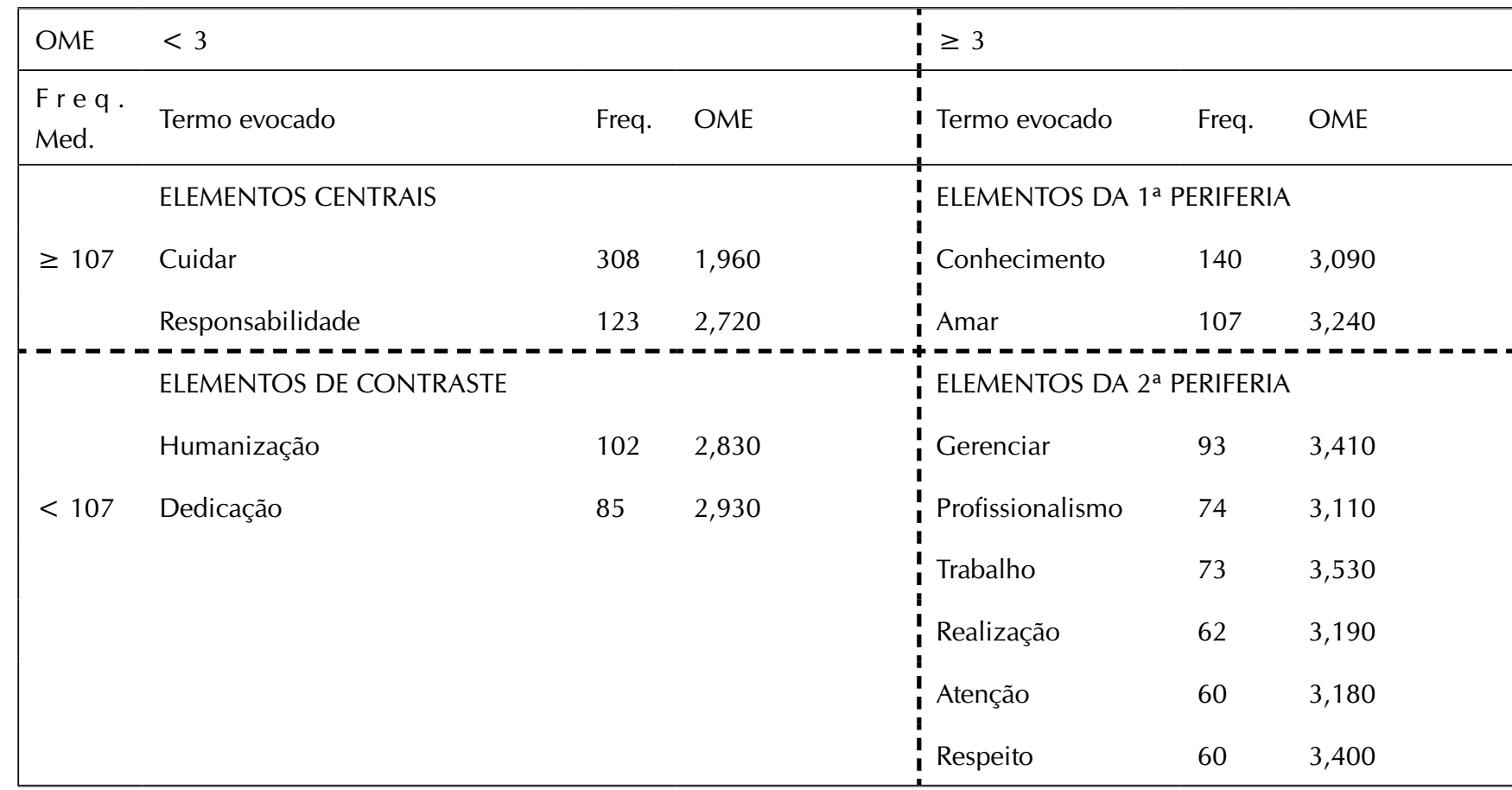

Fonte: Dados primários levantados por meio do questionário aplicado aos sujeitos do estudo.

Nota: Frequência mínima: 60; Frequência média: 107; OME - Ordem média de evocação: 3; Número de discentes.

\section{Quadro 1- Quadro de quatro casas ao termo indutor ser enfermeiro do conjunto de discentes de Enfermagem alocados em Instituições de Ensino Superior privadas. Belo Horizonte-MG, 2007}

O Quadro 1 permite evidenciar a seguinte distribuição das palavras: no quadrante superior esquerdo, os termos cuidar e responsabilidade configuram-se como os possíveis elementos centrais da representação; no quadrante superior direito encontram-se as evocações conhecimento e amar, elementos da $1^{\text {a }}$ periferia; por sua vez, os elementos de contraste, localizados no quadrante inferior esquerdo, estão representados pelas palavras humanização e dedicação; e por último, gerenciar, profissionalismo, trabalho, realização, atenção e respeito representam os elementos da $2^{\text {a }}$ periferia, situados no quadrante inferior direito.

Os elementos centrais referem-se às palavras cuja frequência e ordem prioritária de evocação tiveram maior importância no esquema cognitivo dos sujeitos. Os elementos da $1^{\text {a }}$ periferia referem-se aos termos mais importantes que tiveram frequência maior e Ordem Média de Evocações (OME) maior ou igual ao rang. Os elementos de contraste correspondem aos termos de menor frequência e OME menor que o rang, enquanto os elementos da $2^{\mathrm{a}}$ periferia são os menos importantes que tiveram frequência menor e OME maior ou igual ${ }^{(12-7)}$.

Observa-se que, para o conjunto dos sujeitos deste estudo, o significado de ser enfermeiro está atrelado a elementos que traduzem valores afetivos e atitudinais, como também a representações que remetem à integralidade da assistência prestada, identificados pelas palavras cuidar e responsabilidade.

Na evocação cuidar, elemento de maior frequência e o mais prontamente evocado, os discentes referem-se a uma ação que favorece a manutenção ou melhoramento da condição humana por meio da promoção, manutenção e/ou recuperação da saúde (cuidados com a saúde, diagnosticar, medicar, recuperação dos pacientes, reabilitação a saúde, tratamento), ressaltando o cuidado em relação ao outro (cuidado com paciente, cuidado com o próximo, busca de suprir as necessidades do seu cliente), a familiares (cuidados especiais com familiares) e a si mesmo (cuidar de mim para cuidar dos outros). Observa-se, ainda, a incorporação de expressões que remetem ao cuidado integral (assistência integral, cuidar integralmente dos indivíduos necessitados, prestar assistência integralmente), assim como evocações que traduzem o cuidado dividido por tarefas (assistencialista, medicar). As representações sobre o cuidar remetem, assim, à existência de diferentes perspectivas do cuidar-cuidado do ponto de vista relacional, ou seja, na perspectiva do sujeito que cuida e daquele que é cuidado.

Por se tratar do termo de maior frequência e o primeiro lugar em importância em função da ordem evocada, o termo cuidar reforça a imagem da Enfermagem como uma das profissões da área de saúde cuja essência e especificidade é o cuidado ao ser humano(13).

Vale lembrar que o termo "cuidado" deriva do antigo inglês carion que como verbo "cuidar" significa ter preocupação por, ou sentir uma inclinação ou preferência, ou ainda, respeitar/considerar no sentido de ligação de afeto, amor, carinho e simpatia ${ }^{(14)}$. A Enfermagem, antes de sua institucionalização, existia nas práticas e no ofício de ajudar o próximo, o que remete, ainda hoje, uma ligação com o feminino(15). Mediante as necessidades dos indigentes, desenganados e desamparados, a tarefa de cuidar passou a constituir uma 
motivação para as consagradas que, pela fé, adotavam essa atividade como uma convicção religiosa, de caridade e imagem maternal, que, posteriormente, serviu de base para a profissão. Por isso, a partir do momento histórico da instituição da profissão a imagem social do enfermeiro é ancorada na dedicação e disponibilidade para auxiliar e acolher os outros em suas necessidades.

Essas ideias encontram eco na afirmação de alguns autores ${ }^{(16)}$ que atestam a permanência ao longo da história da associação de vários estereótipos à imagem do enfermeiro, que não acompanharam a evolução técnico-científica da profissão.

[...] a sensibilidade pode expressar-se pelo modo mais afetuoso, carinhoso e de maior dedicação, no atendimento daquelas necessidades que demandam ouvir, sentir e participar dos problemas e emoções da pessoa doente. Há uma tendência natural dos profissionais da enfermagem de envolver-se com essas ações, uma vez que isso faz parte do seu métier e que, de modo efetivo, parece estar relacionado às ações subjetivas da profissão e da convivência intensa com o cliente, na sua jornada de trabalho ${ }^{(17)}$.

Verifica-se, assim, que, no atual contexto, tem ocorrido uma ampliação do conceito cuidar, o que remete à complexidade do termo, referindo-se tanto ao cuidado direto quanto ao indireto, na dimensão da integralidade do cuidado. Tal fato reforça a necessidade de refletir o cuidado em todas as suas dimensões na formação do enfermeiro(18).

O conhecimento (elemento da $1^{\mathrm{a}}$ periferia de maior frequência e o mais prontamente evocado) é outra representação relevante sobre o ser enfermeiro para os discentes entrevistados para a fundamentação deste estudo. Os discentes não o consideram apenas em suas dimensões técnico-científicas e empíricas, mas também nos seus aspectos teóricos e práticos, ocorrendo, inclusive, menção à pesquisa (conhecimento técnico, conhecimento científico, conhecimento técnico científico/conhecimento empírico - senso comum, possuir conhecimento teórico, saber colocar em prática os conhecimentos, pesquisa científica). Na leitura dos dados, percebe-se que esse termo pode estar associado ao atributo cuidar, conforme é exemplificado pelos termos cuidar do outro com bases científicas e técnicas; saber entender e prestar os cuidados de forma correta. $\mathrm{O}$ atributo de conhecimento científico como componente do cuidar em Enfermagem tem sido objeto de análise dessa categoria profissional, uma vez que, durante muito tempo, não teve a necessária evidência, prejudicando, inclusive, a imagem da profissão no conjunto das profissões de saúde ${ }^{(19)}$.

O conhecimento constitui [...] condição indispensável para um posicionamento profissional, distinto, diferenciado, o qual não passa despercebido, nem ao mais grave dos pacientes, uma vez que seus familiares observam a qualidade e a forma como os cuidados são prestados ${ }^{(20)}$.

A postura científica contrapõe-se à submissão, à medida que enfermeiros tornam-se conscienciosos do seu papel de executor de um serviço que objetiva fornecer ao paciente uma assistência integral e contínua, considerada em seus objetivos e metas, conforme seja seu grau de necessidades afetadas ${ }^{(20)}$. Não obstante, faz-se necessário ter consciência científica, a qual vem sendo consideravelmente ampliada, com a evolução da profissão.

A esse respeito cabe mencionar o estudo realizado por Brito sobre a configuração identitária de enfermeiras no contexto das práticas gerenciais em hospitais privados de grande e médio porte de Belo Horizonte. Nesse estudo verificou-se que o conhecimento adquirido ao longo da trajetória profissional das gerentes pesquisadas, no âmbito assistencial e gerencial tem sido determinante para o alcance de maior reconhecimento social e profissional do grupo. Tal reconhecimento é explicitado pelos superiores, subordinados e pares e reflete positivamente na imagem da Enfermagem no contexto dos hospitais utilizados como cenário de estudo e nos espaços de convívio social dessas gerentes ${ }^{(21)}$.

Observa-se, ainda, a incorporação do termo amar (amar ao próximo; ser caridoso; caridade; caridoso; compaixão; é ter compaixão) na $1^{\text {a }}$ periferia, reforçado pelo atributo dedicação (dedicação, justa, se dedicar ao máximo) situado entre os elementos de contraste. Essas duas evocações parecem apontar para a ideologia religiosa caritativa do cuidar, a qual se ancora no próprio contexto histórico social da Enfermagem, demonstrando a persistência no imaginário social da figura do enfermeiro como um profissional que se doa integralmente, mesmo nas relações profissionais ${ }^{(22)}$.

Outra palavra que remete ao cuidar refere-se ao termo humanização, elemento de contraste de maior frequência e o mais prontamente evocado, entendido pelos discentes em diferentes dimensões. Uma dessas dimensões diz respeito à humanização do atendimento (atendimento humanizado, é ser generoso, é ser mais humano, ter interesse no outro), emergindo, assim, o enfoque relacional da subjetividade humana.

Outro aspecto relevante diz respeito ao atendimento integral, que remete ao caráter da humanização agregando outros valores como o conhecimento e a profissionalização do cuidado. O cuidar, presente no elemento central, e o conhecimento, situado na $1^{\text {a }}$ periferia, reforçados pelo termo humanização, encontrado entre os elementos de contraste, expressam a dimensão do atendimento integral.

Segundo o Programa Nacional de Humanização Hospita$\operatorname{lar}(\mathrm{PNHAH})$ da Secretaria de Assistência à Saúde, do Ministério da Saúde,

[...] a humanização é entendida como valor, na medida em que resgata o respeito à vida humana. Alcança circunstâncias sociais, éticas, educacionais e psíquicas presentes em todo o relacionamento humano. Esse valor é definido em função de seu caráter complementar nos aspectos técnico-científicos que privilegiam a objetividade, a generalidade, a casualidade e a especialização do saber ${ }^{(23)}$.

Contribuindo para a melhor compreensão dos significados que remetem à humanização, concordamos que o movimento crescente de cientificidade confere maior expressividade 
ao termo, na medida em que ocorre a expansão e divulgação do paradigma holístico nas ciências. Esse fato se caracteriza pela complementaridade, pelo diálogo entre as diversas formas de conhecimento e pela visão do homem em suas múltiplas dimensões ${ }^{(24)}$.

Por sua vez, o termo responsabilidade, elemento central de menor frequência e que foi evocado mais tardiamente, é compreendido pelos discentes como um comprometimento estabelecido no ato de cuidar, como pode ser percebido por meio das expressões; responsabilidade com o cliente, responsabilidade social, responsável pela recuperação e bem-estar do paciente, estará lidando com vidas. A responsabilidade individual é inalienável a cada um pelo que faz. Todo o cuidado e sensibilidade são fundamentais para tomar decisão em uma instituição, visto que muitos são atingidos pelo modo como se processa a tomada de decisão e por aquilo que se decide ${ }^{(25)}$.

A responsabilidade como elemento integrante do núcleo central pode, assim, sinalizar superações nos estereótipos, rótulos e preconceitos historicamente presentes na Enfermagem, para maior autoestima e valorização da profissão. Essa superação poderá refletir positivamente para a imagem do enfermeiro, além de apontar a necessidade deste profissional se reorganizar para assumir uma dimensão maior no trabalho em saúde, através da implementação de estratégias para intervir de forma fundamentada no processo de cuidar, rompendo com aquela identidade estabilizada, expressando, assim, seu significar na equipe de saúde, afastando-se de ações submissas e pouco expressivas ${ }^{(26)}$.

Os estereótipos, rótulos, preconceitos [...] podem até mesmo ter implicação sobre o caráter de [...] responsabilidade da/o enfermeira/o que, ao assimilar o estereótipo e considerar-se de fato inferior, poderá não se julgar apta a exercer funções e competências que a ela cabem, esquivando-se, passando-os a outrem, o que ajudaria a alimentar o estereótipo, o qual, ao ser reforçado, se voltaria com mais força contra o profissional(20).

Tomando como base as considerações apresentadas, a responsabilidade se expressa como uma atitude muito cobrada no cotidiano do enfermeiro e encontra-se, no atual contexto, diretamente ligada ao conhecimento e a autonomia, principalmente no que diz respeito àqueles adquiridos durante a formação acadêmica.

Ressalta-se, assim, a relevância do desenvolvimento de competências e habilidades que subsidiem o exercício profissional do enfermeiro nos diferentes cargos de atuação.

É importante salientar, ainda, que o gerenciar, elemento da $2^{\text {a }}$ periferia de maior frequência, é apreendido por dois modelos de gestão. Um deles remete aos referenciais da Escola Clássica, conforme se observa nos termos administrador, burocracia, comandar, ser chefe e não apenas subordinada. $\mathrm{O}$ outro diz respeito à gerência vinculada às teorias contemporâneas da administração, exemplificada pelas palavras; articulador, coordenar uma equipe, direcionamento, dirigir a equipe, empreendedora, estratégico, estrategista, gerenciador de conflitos, maleabilidade, planejador, traçar planos. Esses resultados demonstram que o gerenciar remete ao termo cuidar, elemento central de maior frequência e menor rang, na medida em que a finalidade do gerenciamento na Enfermagem é a organização do processo de cuidar, tanto em nível individual, quanto coletivo e, para isso, o enfermeiro realiza o gerenciamento do espaço, dos tempos e das pessoas, cumprindo, dessa forma, uma dupla determinação ao organizar o cuidar e ao atuar como suporte para o trabalho de outros profissionais da saúde ${ }^{(27)}$.

Nesse sentido, o termo gerenciar, provavelmente é, entre os elementos periféricos, aquele que melhor estabelece a interface entre o núcleo central e a realidade concreta na qual são elaboradas e funcionam essas representações para o grupo de discentes pesquisados ${ }^{(28)}$.

A incorporação desses dois modelos sugere que o exercício gerencial do enfermeiro vem passando por uma transição, organizando-se, por um lado, sob a lógica do conservadorismo, e, ao mesmo tempo, seguindo uma tendência de mudanças nessa prática, consequência da própria realidade atual, que exige novos referenciais para a sobrevivência e funcionamento eficiente das instituições. Dessa forma, a administração contemporânea requer das instituições descentralização, flexibilidade, organização por processos, desburocratização, abertura e diversificação. A esse respeito, encontramos que

[...] a busca da flexibilidade se deu ao longo dos anos, a partir das constatações crescentes de que as antigas propostas de rigidez estrutural, baseadas na antecedência da estrutura sobre outras dimensões organizacionais, não mais se coadunavam com a realidade, nem com as necessidades das empresas e instituições públicas no mundo contemporâneo ${ }^{(29)}$.

Para atender a essas novas exigências e resgatando a função gerencial do enfermeiro, observa-se que esse profissional vem se apropriando de referenciais que possibilitem melhor qualificar sua prática. O gerenciamento de conflitos e negociação, o planejamento estratégico, o empreendedorismo e a Sistematização da Assistência de Enfermagem convergem para a responsabilidade do enfermeiro-gerente, que, quando inova sua prática, deixa emergirem novas possibilidades de intervenção na assistência, promovendo a gerência do cuidado. Consegue-se desconstruir, assim, a imagem de que "na saúde e na enfermagem, os processos de cuidar e administrar quase não se tocam, configurando-se em eixos distintos que têm corrido em paralelas" ${ }^{\prime(30)}$.

Outro elemento presente na $2^{\mathrm{a}}$ periferia diz respeito ao profissionalismo, elemento mais prontamente evocado. Observa-se que essa expressão parece remeter ao significado de "ter uma profissão", conforme pode ser verificado nas expressões profissional, profissionalismo, ser profissional, ter uma profissão e não ser a Enfermagem um trabalho que se aproxima ao do tipo profissional.

O enfermeiro [...] domina os conhecimentos relativos ao exercício do trabalho assistencial da enfermagem e tem alguma autonomia para avaliar necessidades assistenciais do 
paciente, decidindo sobre cuidados, o que o aproxima do trabalho do tipo profissional. Mas o trabalho da enfermagem é um trabalho assalariado, subordinado às regras da instituição e, majoritariamente, é organizado sob a lógica da divisão parcelar do trabalho(31).

Cabe salientar que o trabalho também se constitui em um dos elementos da $2^{\text {a }}$ periferia, o que merece destaque tendo em vista sua ligação com a responsabilidade presente no provável núcleo central. O trabalho remete ao termo responsabilidade, principalmente do ponto de vista financeiro, sendo entendido pelos discentes, sobretudo, como a oportunidade para ascensão pessoal, profissional e financeira que melhor satisfaz as necessidades individuais de um ser que se insere na lógica do trabalho produtivo, conforme expresso: apresentam boas chances de emprego, satisfação financeira, independência financeira, colocação no mercado, crescer na profissão e crescimento próprio pessoal.

Observa-se que, para os sujeitos da pesquisa, o trabalho remete ao modo-de-ser-trabalho, que segundo Boff, se dá na forma de inter-ação e de intervenção do indivíduo no modo-de-ser-no-mundo pelo trabalho, sendo por meio do trabalho que se constrói o "habitat", adaptando o meio segundo o desejo e conformando esse desejo ao meio $^{(32)}$.

Esse estudioso alerta quanto ao fato de que, primitivamente, o trabalho era mais inter-ação do que intervenção, uma vez que o homem venerava a natureza, utilizando apenas aquilo que necessitava para sobreviver e tornar mais segura e prazerosa a existência. A partir do momento em que esse indivíduo passou a direcionar-se no sentido de formar as culturas como modelação de si mesmo e da natureza, abriu-se caminho para a vontade de poder e de dominação sobre a natureza. A lógica do ser-no-mundo no modo de trabalho passou, consequentemente, a configurar-se na dominação sobre as coisas, colocando-as a serviço dos interesses pessoais e coletivos e no centro de tudo o ser humano, dando origem ao antropocentrismo.

Essa atitude de trabalho-poder sobre o mundo concretiza a ditadura do modo-se-ser-trabalho-dominação, a qual, nos dias de hoje, conduz "a humanidade a um impasse crucial: ou pomos limites à voracidade produtivista associando trabalho e cuidado, ou vamos ao encontro do pior" ${ }^{\prime \prime 22}$.

Como reflexo desse modo-de-ser-trabalho, os discentes pesquisados revelam, em suas representações, a incorporação do aspecto negativo proveniente da lógica do mercado (mais de um emprego, muito trabalho, plantão, medo do futuro profissional, esforço, trabalhar muito e trabalho árduo), que muitas vezes torna o trabalho alienado, impondo-se à vida das pessoas como algo que os reduz à máquina de produzir riquezas. A força de cada pessoa é traduzida em trabalho e o desgaste de energia física é exigido como se fosse normal em busca da subsistência. No tocante a isso, o trabalhador se torna expropriado ${ }^{(33)}$.

$\mathrm{Na}$ Enfermagem, verifica-se que grande parte dos profissionais submete-se a condições de trabalho geralmente insatisfatórias, como, por exemplo, as duplas jornadas o que acarreta sofrimento a esse profissional, estendendo-se, consequentemente, à família e sociedade.
Nesse sentido, verifica-se que a realização, elemento da $2^{\mathrm{a}}$ periferia, do futuro profissional poderá ser comprometida, uma vez que depende do autoconhecimento, do sentir profissional (autorrealização profissional) e da satisfação sentida em desenvolver o trabalho (fazer o que gosto, gostar do que faz), condições manifestadas pelos discentes, conforme as expressões acima destacadas. Além disso, a realização depende também da valorização, do desenvolvimento e do reconhecimento, evocação pouco significativa para os discentes em foco neste estudo, oferecido por meio de uma relação humanística influenciando na qualidade de vida dos profissionais da Enfermagem ${ }^{(34)}$.

Sobre os elementos da $2^{\text {a }}$ periferia, verifica-se, ainda, que os termos atenção e respeito foram os de menor evocação e parecem remeter ao atributo cuidar. A palavra atenção privilegia as tecnologias leves, ou seja, as ligadas a aspectos relacionais, conforme pode ser evidenciado pelas expressões estar sempre atento, escutar, ouvinte, ouvir, saber ouvir e ter percepção ${ }^{(35)}$. O respeito refere-se, por sua vez, a um comportamento do cuidador que remete a interagir com o outro de forma honesta, sincera e justa, tratando e sendo tratado como ser humano (respeitar cada indivíduo como um ser completo e não apenas como uma doença, respeito à vida, ter respeito e ser respeitado, tratar a todos com igualdade).

Por fim, destaca-se que a Teoria das Representações Sociais foi indispensável para compreender a visão de mundo que os discentes têm sobre o ser enfermeiro, bem como defender a hipótese de que a representação social organiza-se em torno de elementos centrais ligados ao pensamento social, possibilitando ordenar e entender a realidade dos indivíduos ou grupos $^{(36)}$. Dessa forma, o núcleo central consiste em um subconjunto da representação, composto de um ou alguns elementos cuja ausência desestruturaria a representação ou the daria uma significação completamente diferente. Em complemento a este núcleo, encontra-se o sistema periférico, composto por elementos que articulam entre si o sistema central e a realidade vivida ${ }^{(36)}$. É o sistema periférico o responsável pela flexibilidade das representações sociais, suportando a heterogeneidade do grupo e suas contradições.

\section{CONSIDERAÇÕES FINAIS}

Os resultados deste estudo, embora não permitam generalizações, por se tratar de uma realidade específica, permitiram a obtenção de informações úteis sobre as representações sociais de discentes de Enfermagem de IES privadas de Belo Horizonte sobre "ser enfermeiro".

As representações sociais do "ser enfermeiro" para o conjunto dos sujeitos do estudo têm um provável núcleo central alicerçado no cuidar e na responsabilidade. Entre os elementos da $1^{\text {a }}$ periferia destacaram-se as palavras conhecimento e amar; enquanto humanização e dedicação representaram os elementos de contraste. Por sua vez, os elementos da $2^{\text {a }}$ periferia foram constituídos pelos termos gerenciar, profissionalismo, trabalho, realização, atenção e respeito.

Algumas dessas diferenças ocorreram em função das questões de gênero que influenciam na compreensão social do ser enfermeiro, a exemplo das evocações iniciativa, habilidade 
e profissionalismo mais frequentes entre discentes do sexo masculino e humanização, dedicação e equipe para o sexo oposto. Ressalta-se que a carga histórica presente na Enfermagem ainda persiste nos dias atuais, moldando-a em um saber e um fazer específico, ligado aos sentimentos e comportamentos valorizados e norteados por aspectos humanos, éticos e religiosos. Assim, o discurso sobre a formação generalista, autonomia, flexibilidade, pluralidade, integração e interdisciplinaridade estabelecido nas Diretrizes Curriculares para Enfermagem, nem sempre condiz com as ações desenvolvidas, revelando noções amplas e ambíguas para aqueles que esperam uma formação prescritiva e uniformizadora. Faz-se necessário, assim, rever concepções, atualizar valores e fazer escolhas em prol da formação de profissionais críticos e reflexivos, compromissados socialmente com o trabalho coletivo e individual em saúde.

\section{REFERÊNCIAS}

1. Brasil. Lei n. 8.080 de 19 de setembro de 1990. Dispõe sobre as condições para a promoção, proteção e recuperação da saúde, a organização e o funcionamento dos serviços correspondentes e dá outras providências. Diário Oficial da República Federativa do Brasil, Poder Executivo, Brasília, DF, 20 set. 1990. Seção 1.

2. Brasil.Ministério da Saúde. Ministério da Educação. Programa Nacional de Reorientação da Formação Profissional em Saúde - Pró - Saúde: objetivos, implementação e desenvolvimento potencial/ Brasília; 2007.

3. Instituto Nacional de Estudos e Pesquisas Educacionais - INEP. Cadastro das Instituições de Educação Superior. 2007. [citado em 04 dez. 2007]. Disponível em: < http:// www.inep.gov.br $>$.

4. Ministério da Educação e do Desporto -MEC. Sistema Nacional de Avaliação da Educação Superior: da concepção à regulamentação. 4. ed. ampl. Brasília: Instituto Nacional de Estudos e Pesquisas Educacionais Anísio Teixeira, 2007.

5. Brasil.Ministério da Educação e do Desporto. Conselho Nacional de Educação. Câmara de Educação Superior. Diretrizes Curriculares Nacionais do Curso de Graduação em Enfermagem. Resolução CNE/CES n. 3, de 7 de novembro de 2001. Institui Diretrizes Curriculares Nacionais do Curso de Graduação em Enfermagem. Diário Oficial da União, Brasília, 9 nov. 2001. Seção 1. p. 37.

6. Garanhani, M. L. Princípios pedagógicos e metodológicos do currículo integrado de Enfermagem. In: Dellaroza MSG, Vannuchi MTO. (Org.) O currículo integrado do curso de enfermagem da Universidade Estadual de Londrina: do sonho à realidade. Editora HUCITEC: São Paulo; 2005:3:35-57.

7. Sá CP de. Núcleo central das representações sociais. Petrópolis: Vozes; 2002.

8. Oliveira DC, Marques SC, Gomes AMT, Teixeira MCTV. Análise das evocações livres: uma técnica de análise estrutural das representações sociais [No Prelo]. 2003.

9. Ensemble de Programmes Permettant L'analyse des Evocations - EVOC. Conjunto de programas que permitem a análise de evocações [Apostila] versão 5. Manual Provence, 2003.

10. Brasil. Ministério da Saúde. Conselho Nacional de Saúde. Resolução no 196, de 10 de outubro de 1996. Aprova as diretrizes e normas regulamentadoras de pesquisas envolvendo seres humanos. Informe epidemiológico do SUS, Brasília, V(2), 1996. Suplemento 3.
11. Vergès P. Approche du noyau central: propriétés quantitatives et structurales. In: Guimelli C. Structures et transformations des representations sociales. Lausanne: delachaux et Niestlé, 1994: 233-254.

12. Abric JC. Pratiques sociales et représentations. Paris: Presses Universitaires de France, 1994.

13. Leininger MM. Transcultural Nursing: concepts, theories and practice. New York: John Wiley, 1978.

14. Gaut D. Development of a theoretically adequate description of caring. Western Journal of Nursing Research 1983:5(4): 313-24

15. Collière MF. Promover a vida: da prática das mulheres de virtude aos cuidados de enfermagem. Lisboa: Printipo Indústrias Gráficas; 1989.

16. Braga MS, Bersusa AAS. Imagem do enfermeiro sob a ótica de médicos e do próprio profissional. In: $47^{\circ}$ Congresso Brasileiro de Enfermagem. Goiás. 1995: ABEn.

17. Pereira Á. O quotidiano profissional do enfermeiro: das aparências às diferenças de gênero. [Série Teses em Enfermagem, 17] Pelotas: Editora Universitária/UFPel; Florianópolis: UFSC, 1999.

18. Silva KL e Sena RR. A formação do enfermeiro: construindo a integralidade do cuidado Rev Bras Enferm 2006:59(4):488-91.

19. Vieira MJ. A representação do cuidar na imagem cultural da enfermagem. Revista Latin-Am. Enf 1999: 7(5):25-31.

20. Rodrigues MSP. Enfermagem: representação social das/os enfermeiras/os. [Série Teses em Enfermagem, 18]Pelotas: Editora Universitária/UFPel; Florianópolis: UFSC, 1999.

21. Brito MJM. A configuração identitária da enfermeira no contexto das práticas de gestão em hospitais privados de Belo Horizonte [Tese Doutorado em Administração]. - Faculdade de Ciências Econômicas da Universidade Federal de Minas Gerais, Belo Horizonte, 2004.

22. Stacciarini JM, Andraus LMS, Esperidião E e Nakatani A.K. Quem é o enfermeiro? Rev Eletr Enf 1999:1(1) [citado em 18 abr.2007]. Disponível em: <http://www.fen.ufg.br >

23. Brasil. Ministério da Saúde. Secretaria de Assistência à Saúde. Programa Nacional de Humanização da Assistência Hospitalar - PNHAH. Brasília: Ministério da Saúde, 2001b. 60 p. (Série C. Projetos, Programas e Relatórios, 20).

24. Crema R. Abordagem holística: integração do método analítico e sintético. In: Brandão DMS, Crema R. O novo paradigma holístico. São Paulo; 1991: 2: 83-99. 
25. Leisinger KM, Schmitt K. Ética empresarial: responsabilidade global e gerenciamento moderno. Rio de Janeiro: Vozes; 2001.

26. Bueno FMG, Queiroz MS. O enfermeiro e a construção da autonomia profissional no processo de cuidar. Rev Bras Enferm 2006: 59(2): 222-7.

27. Leopardi MT, Gelbcke FL, Ramos FRS. Cuidado: objeto de trabalho ou objeto epistemológico da Enfermagem? Tex \& Cont. Enf. Florianópolis Jan./Abr. 2001: 10(1) 32-49.

28. Marques SC, Oliveira DCde, Gomes AMT. AIDS e representações sociais: uma análise comparativa entre subgrupos de trabalhadores. Psicologia: Teoria e Prática 2004: 6(especial):91-104.

29. Motta PR. Gestão contemporânea: a ciência e a arte de ser dirigente. Rio de Janeiro; 1991.

30. Ferraz CA. As dimensões do cuidado em enfermagem: enfoque organizacional. Acta Paulista Enf 2000:13(especial)91-97.

31. Pires D. O processo de trabalho em saúde. In:Pires D. Reestruturação produtiva e trabalho em saúde no Brasil. São Paulo: Confederação Nacional dos Trabalhadores em Seguridade Social -CUT; Annablume, 1998. (VI): 158-203.

32. Boff L. Saber cuidar: ética do humano - compaixão pela terra. Petrópolis, 1999.

33. Neumann VN. Qualidade de vida no trabalho: percepções da equipe de enfermagem na organização hospitalar. [Dissertação Mestrado em Enfermagem]-Escola de Enfermagem, Universidade Federal de Minas Gerais, Belo Horizonte, 2007.

34. Lentz RA, Costenaro RGS, Gonçalves LHT, Nassar SM. O profissional de enfermagem e a qualidade de vida: uma abordagem fundamentada nas dimensões propostas por Flanagan. Rev Latin Am Enf. 2000: 8(4): 7-14.

35. Merhy EE, Franco TB. Por uma Composição Técnica do trabalho em saúde centrada no campo relacional e nas tecnologias leves. Apontando mudanças para os modelos tecno-assistenciais. Saúde em Debate, Rio de Janeiro Set./ Dez. 2003: 27(65):316-323.

36. Abric JC. Les représentations sociales: aspects théoriques. In: _. Pratiques sociales et représentations. 2ed. Paris: Presses Universitaires de France; 1997. Chap. 3: 59-82. 